\title{
Development and Application of an Offline Learning System in College Teaching
}

\author{
http://dx.doi.org/10.3991/ijet.v10i5.4794 \\ Xiaoyan Zhong \\ Hunan First Normal University, Changsha, China
}

\begin{abstract}
With the improvement of science and technology and the popularization of the internet, offline teaching and multimedia teaching are standing out compared to traditional teaching. This paper summarizes the design content and requirements of physical education teaching in an offline learning system, designs the framework and core module for offline teaching according to the requirements of a college physical education curriculum, and finally designs the offline learning system for the physical education curriculum. This system can meet students' offline learning requirements and, in some aspects, is compatible with an online learning mode based on SCORM standards. Empirical study of the system's operation and application proves that an offline learning system for a physical education curriculum has significant teaching effects.
\end{abstract}

Index Terms—offline learning, system, development, college physical education

\section{INTRODUCTION}

With the improvement of science and technology and the popularization of the internet, colleges and universities nationwide are starting to adopt multimedia teaching on a large scale. Compared with a traditional teaching mode, network multimedia teaching is characterized as saving teaching resources and making it more convenient for students to acquire knowledge [1]. But online-based multimedia teaching has a fatal defect; that is, students cannot learn when they cannot connect to the campus network. Additionally, when all students study online at the same time, it is necessary to have a large bandwidth [2]. Thus, bandwidth can also be a limiting factor. So, it is very important to develop and research long-distance and offline multimedia teaching modes and systems for colleges.

An offline learning system is a type of client procedure that can allow users to study courses using their personal computer as well as allow faculty to track and record their learning. Students can download encrypted teaching course material and achieve real-time learning by installing an offline learning system. Students' learning schedule and assignment completion are automatically recorded by the system. After they finish, they need to upload their work to the main platform of the system to have their information recorded [3].

With regard to the development and application of an offline learning system in physical education teaching, some researchers [4] point out that the offline teaching mode adopted in America teaches physical education by level and grades offline learning content based on students being at different levels and needing different teaching methods for different content. Numerous American schol- ars add curriculum education about healthy lifestyles in the offline teaching content as well as teaching methods that are closely related to daily life. There is also corresponding curriculum content for students of different ages/grades. Generally speaking, American college physical education teaching has formed a complete offline learning system.

Steedman et al. [5] suggests that the Japanese mobile internet has become popular and that its multimediaassisted teaching is also relatively sound. At present, Japanese college physical education teaching is set in accordance with different time brackets and age groups. Students with sufficient time may select multiple curricula or content for age groups they are interested in. Furthermore, Japan's offline physical education teaching allows students to study the content of a chapter several times. This ensures full utilization of fragmented time.

Hills et al. [6] points out that modernization of the theoretical foundation of physical education in the near future will not just save common resources such as classrooms but will also contribute to relieving the pressure of insufficient professional teachers in physical education. Franko et al. [7] proposes that the combination of physical education teaching and independent study via the internet can extend learning the content and effectively relieve many practical problems such as large differences in physical quality and different learning needs.

Development of offline learning seeks to adapt the mode of teaching modern physical education, solve the shortage of teacher resources in colleges, and meet the different requirements for teaching content to students with diverse physical quality. However, the development and application of offline learning systems are just in the initial stage. There are still shortcomings in some aspects. Thus, designing an offline teaching system that can combine physical education teaching content and methods has feasibility and practical application value. This paper presents a new offline learning platform for college-level physical education based on a compatible $\mathrm{B} / \mathrm{S}$ structure and SCORM standard from the perspective of system development and tests its application effect.

\section{DEVELOPMENT OF OFFLINE LEARNING SySTEM}

An offline learning system has the following property requirements: (1) the working performance of the system is stable with good compatibility, and the operating environment of the system should satisfy the configuration of most computers with good compatibility; (2) it should have data recording and tracking functions; and (3) it should have a data encryption function. Since an offline learning system allows use of an external network to log 
in, once encrypted files are disclosed, all curriculum assignments, learning content and examinations will lose significance. The development of an offline learning system includes two parts. 1) The system architecture and framework mode. The system architecture pattern decides the way the system operates. This study adopted a B/Sbased design. 2) The sub-module design of the system's core. Each function of the system is designed in various modules with different functions in the client for the convenience of backstage operation and management. The following is the offline learning system structure chart. (See Figure 1).

\section{A. Offline learning system module}

Students learn physical education curriculum in the offline state. The database of the offline system has the ability to record students' learning schedules in real time. When the learning in a stage is over, the students need to upload the learning content and schedule to the main platform so they can continue to learn the next time. Offline sub-systems in this system include a teaching content integration sub-system, an encryption and packaging subsystem, a user identification authentication sub-system, an offline learning package downloading and installation sub-system, an offline learning sub-system, a learning schedule recording sub-system, and an offline learning client software installation and update sub-system as well as a USB flash disk automatic detection sub-system.

(1) Courseware integration sub-system: This system is used to analyze and intensively classify streaming media files in the offline teaching content.

(2) Courseware encryption and packaging sub-system: This system is used to achieve encryption and packaging of the offline teaching courseware.

(3) Offline learning package downloading and installation sub-system: This sub-system is used to automatically form the offline learning package, including the offline courseware package and schedule file, to offer automatic detection and downloading functions of the offline learning package and to switch the learning state. The loading sub-system mainly includes the offline courseware package and its corresponding learning schedule information.

(4) Offline learning sub-system: The offline learning sub-system facilitates the users' learning of the courseware. The system generally includes the courseware list, the courseware playing records, the students' learning schedule records, etc.

(5) Learning schedule synchronization sub-system: The learning schedule synchronization sub-system is a platform to achieve unification of the offline learning schedule and the online learning schedule and a synchronous update of data.

(6) Client software installation and update sub-system: The offline learning platform installation and update subsystem installs and updates the client software.

(7) USB flash disk automatic detection sub-system: This sub-system detects the position suitable for courseware information storage in the computer or on a USB flash disk and sends the results to the system. In view of the difference between an offline system and an inline system, the system designed for this project had to meet uniformity, convenience, and compatibility.

\section{B. Architecture pattern of offline learning system}

The system architecture of the offline learning platform adopts a multi-layer architecture. The B/S structure forms a 3-tier structure. Under such a structure, the users' work interface is achieved through the external browser, and a very small part is achieved in the browser. Data storage for the whole backstage adopts the SQLServer database and XML as its media.

\section{1) EXT-JS technology}

Ext-JS is an RCP (rich client platform) AJAX application written with Javascript. It is used to establish the front end user interface of the $\mathrm{B} / \mathrm{S}$ architecture application program. It is unrelated to the backstage technology. For the application programs developed by Ext, Component is the highest-level abstract and is directly used by the users. Ext Element is a bottom-layer API that can be called by Ext or a custom component. DOM is an original API defined by W3C standards. Ext achieves page effect in Ext through the operating DOM. The Corresponding Element of Component can be gained through visiting the attribute of Component, and the DOM object can be gained through visiting the DOM attribute of Element. In addition, we can also acquire the Component and Ext Element as well as the DOM node through shortcut methods of Ext class, such as getCmp, get and getDom.

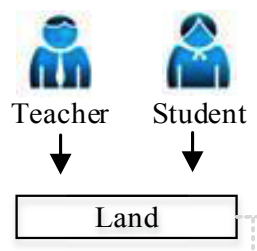

Home page

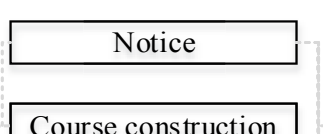

Course construction

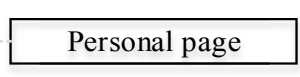

Course ranking

Course display

Major
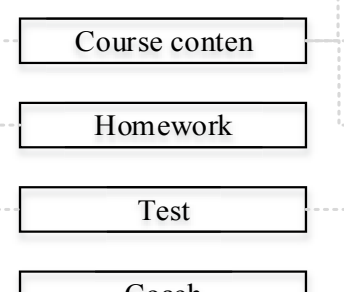

Coach

Student assessment

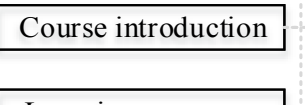

Learning resources
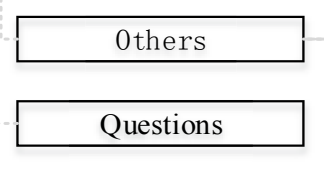

Teacher assessment
Assessment criteria

Teaching purpose

Course notes

Teaching Video

Textbooks

Learning resources

Figure 1. Offline learning system structure 


\section{2) ASP.Net technology}

ASP.Net is expanded technology of the ASP. Due to the simple application of ASP and excellent customization ability, it has become a hot development tool of Web server application programs. Its working principle is that it provides developers with a series of OOP Web application program models. Control of these models operates in the Web server, transforms the user interface into an HTML format, and sends it to the browser. An ASP.Net program is compiled during its first operation. The operating efficiency is much better than that of an ASP program. Compared with other Web development technology, it has the following features and advantages: easy to generate, compatible with scripting language, object-oriented, and easy to protect its object-orientation.

This system adopts Ext-JS technology for the system's front end design and applies ASP.Net technology to transform the Web application program model. The system design adopts OOT, and the client adopts an IE6.0 or above browser. Visual Studio 2008 (C\#) and EXT-JS serve as the front-end development tools. JavaScript serves as the major programming language. The database selects MSSQL2005. In the design and development process, the suitable object and application range of the system strive to reach strong flexibility, high network security, and a friendly user experience.

\section{Design of core sub-system of offline learning}

1) Log-in interface exhibition of offline system (see Figure 2).

This interface is the log-in interface of the offline learning system. Interface design content includes user name, password, and user identity. The design of the "identity information" aims to specify the users' identity and limits authority to prevent users with different limits of authority from operating beyond their limits of authority.

1) Exhibition of offline learning system interface (see Figure 3)

This interface is the main interface of the offline learning system. The interface includes several sub-interfaces. Each sub-interface consists of one or more modules in the system design. This interface can present the students' curriculum selection information, learning state, schedule, daily questions, and assignments. Additionally, the largest advantage of this system is that it can be compatible with

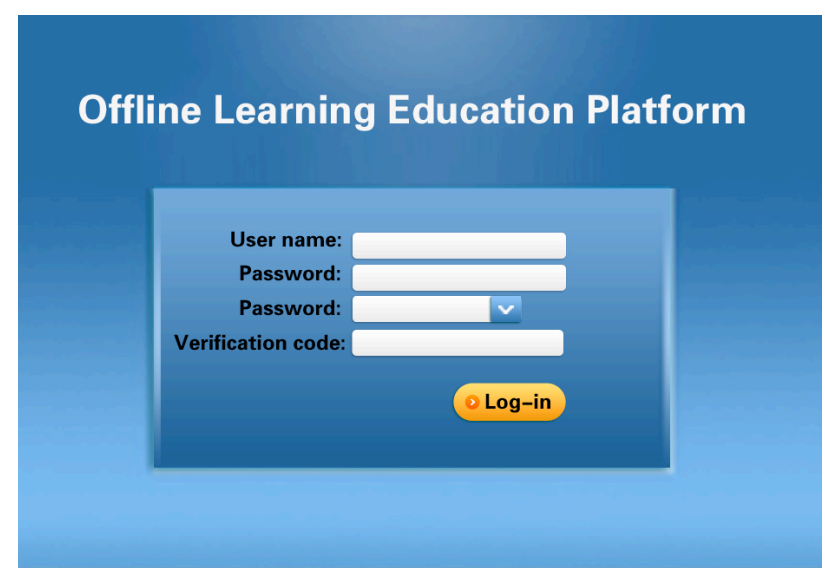

Figure 2. Log-in interface of offline learning system

courseware content based on SCORM standards. Other offline teaching systems do not have such functions.

\section{APPLICATION OF OFFLINE LEARNING SYSTEM IN College Physical Education Teaching}

\section{A. Experimental objects}

For the study, 120 college students were selected at random, including 60 boys and 60 girls. Sixty students in Class 1 were selected for the experimental group, and 60 students in Class 2 were selected for the control group. One hundred twenty questionnaires were issued; 112 completed questionnaires were collected, 22 in the experimental group and 57 in the control group. Students in experimental group used offline teaching to learn the physical education curriculum, while the students in the control group applied an online teaching platform. Knowledge content and teaching arrangement were the same for the two groups (one semester and 56 class hours in total).

\section{B. Learning outcome evaluation methodology}

The experiment comprehensively evaluated the influence of the offline learning system platform on the learning effects of students taking physical education as an elective course from two aspects: (1) final test performance of the physical education curriculum from data obtained through examination and (2) learning selfefficacy. A learning self-efficacy scale prepared by Bian Yufang was used for this investigation.

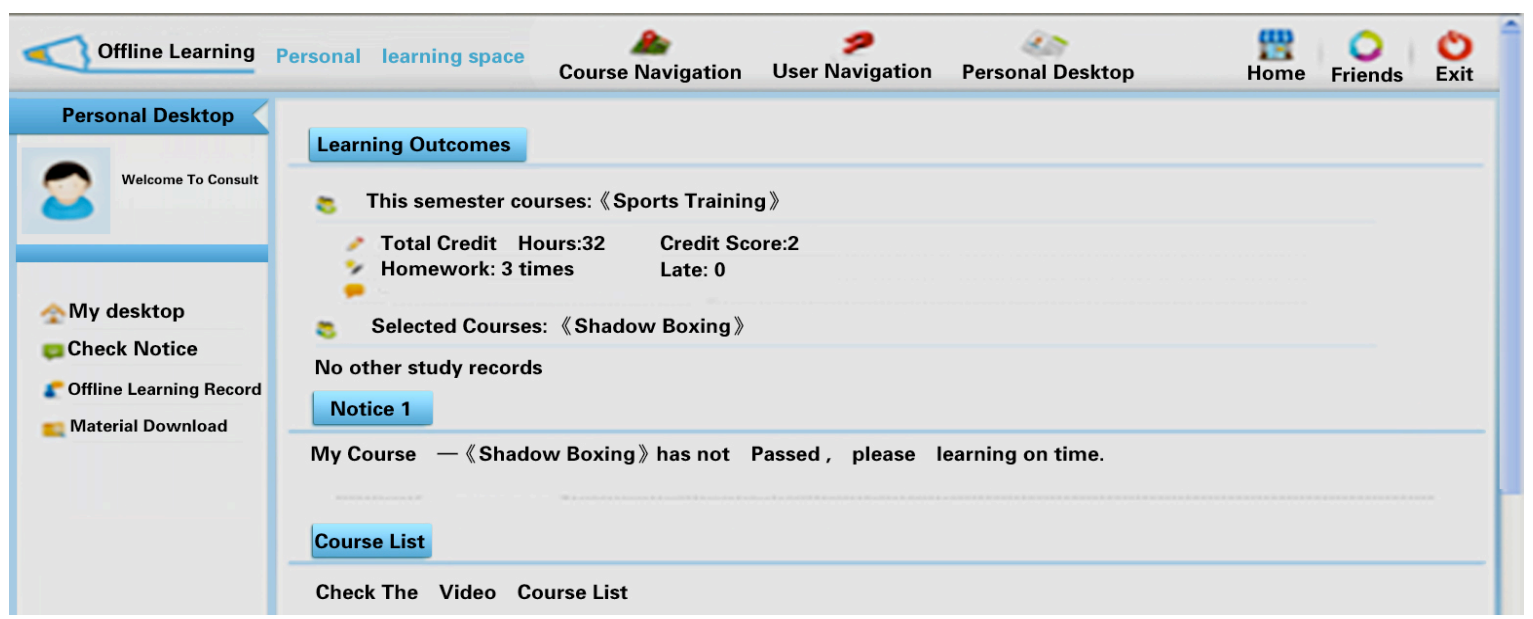

Figure 3. Learning interface of offline learning system 
Statistical method data were analyzed with an SPSS15.0 software package. Quantitative data were expressed with mean \pm standard deviation $( \pm \mathrm{s})$. Quantitative data of the two groups were compared with t-tests. An after and before intervention, intra-group comparison was conducted with paired t-tests. Qualitative data were expressed with case number and constituent ratio. Intergroup comparison of the two groups of qualitative data adopted a chi-square test or rank sum test (orderly data). $\mathrm{P}<0.05$ means the difference has statistical significance.

\section{Experimental results and analysis}

It is seen in Table 1 that before the intervention, the gender, age, physical education results at the end of the last semester, class leader situation, and household economy of the two groups had no statistical significance $(\mathrm{P}>0.05)$. This means the baseline information of the two groups has comparability.

Before the intervention, the physical education results difference of the experimental and control groups had no statistical significance $(\mathrm{t}=1.406, \mathrm{P}=0.163)$. After intervention, the physical education result of both groups improved. The difference has statistical significance, compared with the result before the intervention $(\mathrm{P}<0.05)$. The improvement value of the physical education results in the experimental group is larger than that of control group. The difference has statistical significance $(t=4.590, \mathrm{P}<0.001)$. See Table II for details.

Before the intervention, the scores of the learning selfefficacy of the experimental and control groups had no statistical significance $(\mathrm{t}=0.766, \mathrm{P}=0.446)$. After the intervention, the experimental group's learning self-efficacy score significantly increased compared to before the intervention. The difference has no statistical significance $(\mathrm{P}=0.329)$. The difference in the learning self-efficacy scores of the two groups before and after the intervention have statistical significance $(\mathrm{t}=11.096, \mathrm{P}<0.001)$. See Table III for details.

\section{CONCLUSIONS}

Based on the features of the offline learning system, this project developed an offline teaching software platform for college-level physical education. During the design and development of this system, this project adopted a structural pattern based on Ext-JS and ASP.NET. Relevant programs were modified according to SCORM standards, creating a physical education system that is compatible with other online and offline learning platforms. The experiment proves that an offline teaching mode can enhance students' learning. The results of the students using the offline learning platform are higher than those using an online teaching platform.

This empirical study on an offline learning platform shows the students using the offline learning platform performed significantly better than the students who did not use the offline learning platform in terms of selfefficacy and final comprehensive examination results. This indicates that offline learning platform has a good effect on self-efficacy and skill mastery for college students.

TABLE I.

COMPARISON OF BASELINE INFORMATION OF TWO GROUPS

\begin{tabular}{|c|c|c|c|c|c|}
\hline & Item & Experimental group $(\mathrm{n}=55)$ & Control group $(n=57)$ & $t / \mathbf{z} / \mathbf{c}^{2}$ & $\mathbf{P}$ \\
\hline \multirow{2}{*}{ Gender } & Male & $37(67.3 \%)$ & $36(63.2 \%)$ & 0.27 & 0.600 \\
\hline & Female & $18(32.7 \%)$ & $21(36.8 \%)$ & & \\
\hline \multicolumn{2}{|c|}{ Age } & $19 \pm 3$ & $19 \pm 4$ & 0.127 & 0.899 \\
\hline \multicolumn{2}{|c|}{ Physical education result at the end of the last semester } & $78.3 \pm 7.0$ & $76.3 \pm 8.0$ & 1.406 & 0.163 \\
\hline \multirow{2}{*}{ Class leader situation } & No & $47(85.5)$ & $48(84.2)$ & 0.034 & 0.854 \\
\hline & Yes & $8(14.5)$ & $9(15.8)$ & & \\
\hline \multirow{4}{*}{ Household economy } & Very good & $9(16.4)$ & $12(21.1)$ & 0.104 & 0.917 \\
\hline & Good & $30(54.5)$ & $27(47.4)$ & & \\
\hline & General & $11(20.0)$ & $12(21.1)$ & & \\
\hline & Very poor & $5(9.1)$ & $6(10.5)$ & & \\
\hline
\end{tabular}

TABLE II.

ENGLISH TEST RESULT OF EXPERIMENTAL GROUP AND CONTROL GROUP AFTER EXPERIMENT

\begin{tabular}{c|c|c|c|c|c}
\hline Group & $\begin{array}{c}\text { Before interven- } \\
\text { tion }\end{array}$ & After intervention & Difference value & $\begin{array}{c}\text { Intra-group com- } \\
\text { parison }\end{array}$ & $\begin{array}{c}\text { Inter-group comparison of dif- } \\
\text { ference value }\end{array}$ \\
\hline Experimental group & $78.3 \pm 7.0$ & $85.4 \pm 7.6$ & $7.1 \pm 4.3$ & $\mathrm{P}<0.001$ & $\mathrm{t}=4.590$ \\
\hline Control group & $76.3 \pm 8.0$ & $79.8 \pm 8.1$ & $3.5 \pm 4.0$ & $\mathrm{P}=0.023$ & $\mathrm{P}<0.001$ \\
\hline
\end{tabular}

TABLE III.

COMPARISON OF CHANGES IN LEARNING SELF-EFFICACY BEFORE AND AFTER INTERVENTION

\begin{tabular}{c|c|c|c|c|c}
\hline Group & Before intervention & $\begin{array}{c}\text { After interven- } \\
\text { tion }\end{array}$ & Difference value & $\begin{array}{c}\text { Intra-group com- } \\
\text { parison }\end{array}$ & $\begin{array}{c}\text { Inter-group comparison of } \\
\text { difference value }\end{array}$ \\
\hline Experimental group & $4.32 \pm 0.75$ & $5.12 \pm 0.71$ & $0.80 \pm 0.37$ & $\mathrm{P}<0.001$ & $\mathrm{t}=11.096$ \\
\hline Control group & $4.21 \pm 0.77$ & $4.35 \pm 0.74$ & $0.14 \pm 0.25$ & $\mathrm{P}=0.329$ & $\mathrm{P}<0.001$ \\
\hline
\end{tabular}


PAPER

Development And Application of An OfFLine LeARning System in College Teaching

\section{REFERENCES}

[1] Armenteros M., Liaw S.S., Fernández M., Díaz R.F., Sánchez R.A., "Surveying FIFA instructors' behavioral intention toward the Multimedia Teaching Materials," Computers \& Education, vol. 61, no. 2, pp. 91-104, February 2013. http://dx.doi.org/10.1016/ j.compedu.2012.09.010

[2] Chen H.Y., Liu K.Y., "Web-based synchronized multimedia lecture system design for teaching/learning Chinese as second language," Computers \& Education, vol. 50, no. 3, pp. 693-702, April 2008. http://dx.doi.org/10.1016/j.compedu.2006.07.010

[3] Sohn S.Y., Park H.Y., Chang I.S., "Assessment of a complementary cyber learning system to offline teaching," Expert Systems with Applications, vol. 36, no. 3, pp. 6485-6491, April 2009. http://dx.doi.org/10.1016/j.eswa.2008.07.075

[4] Uludağ G., Kiraz B., Etaner-Uyar A.Ş., Özcan E., "A hybrid multi-population framework for dynamic environments combining online and offline learning," Soft Computing, vol. 17, no. 12, pp. 2327-2348, August 2013. http://dx.doi.org/10.1007/s00500-0131094-7

[5] Steedman M, Abouammoh M, Sharma S., "Multimedia learning tools for teaching undergraduate ophthalmology: results of a randomized clinical study," Canadian Journal of Ophthalmology, vol.
47, no. 1, pp. 66-71, February 2012. http://dx.doi.org/10.1016/ j.jcjo.2011.12.006

[6] Hills A.P., Dengel D.R., Lubans D.R.., "Supporting Public Health Priorities: Recommendations for Physical Education and Physical Activity Promotion in Schools," Progress in Cardiovascular Diseases, vol. 57, no. 4, pp. 368-374, January-February 2015. http://dx.doi.org/10.1016/j.pcad.2014.09.010

[7] Franko D.L., Cousineau T.M., Trant M., Green T.C., Rancourt D., Thompson D., et al., "Motivation, self-efficacy, physical activity and nutrition in college students: Randomized controlled trial of an internet-based education program," Preventive Medicine, vol. 47, no. 4, pp. 369-377, October 2008. http://dx.doi.org/10.1016/ j.ypmed.2008.06.013

\section{AUTHORS}

Xiaoyan Zhong (Corresponding author) is a lecturer in Physical Education Institute, Hunan First Normal University, Changsha 410205, China. Her research interests include college physical education and offline education (xiaoyanzhong12@yeah.net)

Submitted 08 June 2015. Published as resubmitted by the author 30 October 2015. 